\title{
Depression and associated factors among infertile women at Tu Du hospital, Vietnam: a cross-sectional study
}

This article was published in the following Dove Press journal: International Journal of Women's Health

\author{
Tuan M Vo' \\ Quynh TT Tran ${ }^{2}$ \\ Cuong $\mathrm{V} \mathrm{Le} \mathrm{Le}^{3}$ \\ Trang $\mathrm{TH} \mathrm{Do}{ }^{4}$ \\ Thi M Le ${ }^{5}$ \\ 'Department of Obstetrics and \\ Gynecology, University of Medicine and \\ Pharmacy at Ho Chi Minh City, Ho Chi \\ Minh City, Vietnam; ${ }^{2}$ Department of \\ General Gynecology, Tu Du Hospital, Ho \\ Chi Minh City, Vietnam; ${ }^{3}$ The Science and \\ Technology Office, University of Medicine \\ and Pharmacy at Ho Chi Minh City, Ho \\ Chi Minh City, Vietnam; ${ }^{4}$ Department of \\ Disaster Management, Hanoi University \\ of Public Health, Hanoi, Vietnam; \\ ${ }^{5}$ Department of Population and \\ Reproductive Health, Hanoi University of \\ Public Health, Hanoi, Vietnam
}

Correspondence: Thi M Le

Hanoi University of Public health, IA Duc Thang, Bac Tu Liem, Hanoi, Vietnam

Tel +8 49I 2572200

Email Imt@huph.edu.vn

Tuan M Vo

University of Medicine and Pharmacy, 217

Hong Bang St. HCMC, Ho Chi Minh City,

Vietnam

Tel +8490972 7199

Email vominhtuan@ump.edu.vn
Background: About 40,000 infertile couples visit Tu Du Hospital, Vietnam for consultation and treatment of infertility per year. Depression in infertile female patients not only influences mental wellbeing, but also affects the effectiveness of infertility treatment. The study aimed to determine the depression prevalence in infertile female patients and associated factors.

Methods: A cross-sectional study was conducted during April-July 2016 with 401 infertile women visiting the Department of Infertility at Tu Du Hospital. The PHQ-9 scale was used to measure depressive symptoms. Face-to-face interviewing was conducted using a structured questionaire. Participants were also inquired about demographic characteristics, socioeconomic status, infertility related characteristics and family and social relationships.

Results: The depression prevalence was $12.2 \%$, with a cut-off score $\geq 10$ on PHQ-9 scale. Depression in infertile female patients was associated with infertility caused by the husband (AOR=3.09, 95\% CI=1.44-6.63), infertility caused by both spouses (AOR=3.63, 95\% $\mathrm{CI}=1.26-10.48)$, alcohol-addicted husband $(\mathrm{AOR}=4.83,95 \% \mathrm{CI}=1.32-17.58)$, and with wife's previous antidepressant use ( $\mathrm{AOR}=48.1,95 \% \mathrm{CI}=4.83-47.96)$

Conclusions: Assessment of depressive symptoms should be assessed at an early stage among infertile female patients for timely mental health support.

Keywords: infertile female patient, depression, PHQ-9

\section{Introduction}

According to the World Health Organization (WHO), infertility is defined as "the failure to achieve a clinical pregnancy after 12 months or more of regular unprotected sexual intercourse". ${ }^{1}$ It is prevalent in approximately $10 \%$ of couples. ${ }^{2}$ It has been said that infertility affects more people in the developing world, mainly due to infectious diseases that cause damage to the reproductive track, and where there is limited access to fertility services. ${ }^{3}$

Depression, a common mental illness, affects about 121 million people worldwide. The WHO states that depression is the leading cause of disability, as measured by Years Lived with Disability (YLDs), and the fourth leading contributor to the global burden of diseases. By the year 2020, depression is projected to reach second place in the ranking of Disability Adjusted Life Years (DALY) calculated for all ages. Today, depression is already the second cause of DALYs in the age category of 15-44 years. The WHO's depression statistics over the world vary by sex with the prevalence among female being $50 \%$ higher among males. ${ }^{4}$ 
Therefore, depression in females needs special concern because of severe impacts on quality of life. ${ }^{5}$ In the other countries, the prevalence of depression is $5-12 \%$ for men and $10-25 \%$ in infertile women. ${ }^{6}$ Major depression is $2-3$ times as common in women as in men. ${ }^{5}$

Many studies have provided evidence that depression is highly prevalent among infertile women. ${ }^{7}$ It has been reported that depressive symptoms could be the cause of infertility, its consequence, or both. ${ }^{7}$ Psychological consequences of infertility may be related to a wide range of factors, including but not limited to the loss of control over one's life, stigmatization and isolation from the fertile world, the lack of empathy from family and friends, the feeling of guilt and the diminished sense of self-worth, the long and uncertain treatment, and the costs of treatment. ${ }^{8}$ Women are typically the identified patient seeking help in fertility centers. Regardless of which spouse has the reproductive impairment, it is almost always the women who have to undergo the invasive procedures and the daily monitoring of their menstrual cycles and experience disruption in their schedules to follow rigid treatment regimens. Therefore, women carry more psychological burden of infertility, even when the infertility cause comes from their husband. ${ }^{9,10}$

There have been numerous studies addressing the prevalence of depression among Vietnamese people. ${ }^{11-}$ ${ }^{14}$ However, most of these studies focus on the general population. As infertility may have a substantial psychological impact on women as reported by international literature, it is important to have knowledge about this impact on Vietnamese women and its correlates. We conducted a study at $\mathrm{Tu}$ Du Hospital in Ho Chi Minh City, Vietnam, with an aim to estimate the prevalence of depression among infertile female patients and to identify correlates of depression among this patient group.

Built in 1937, Tu Du Hospital is one of the leading hospitals specializing in obstetrics, gynecology, and new-borns. More than 200,000 patients are treated at this hospital each year. ${ }^{15}$ Pondering over the worry of many infertile couples, the hospital has carried out research and applied reproductive-assistance techniques, especially In Vitro Fertilization (IVF), which has brought happiness to many families. An estimated 40,000 infertile couples visited Tu Du Hospital for consultation and treatment of infertility in 2014. ${ }^{16}$ Among those couples, there were failures of assisted reproduction therapy, and the couples with unsuccessful treatment had to return to the hospital many times to repeat the treatment procedures. It can be said that mental well-being played a crucial role in the treatment process, because it influenced the effectiveness of assisted reproduction therapy.

\section{Methods \\ Study design}

This study used a cross-sectional design.

\section{Study participants}

Data of this study were collected between April and July 2016. Participants of this study were all infertile female patients who were seeking treatment for infertility at Tu Du Hospital, which is one of the two National OBGY hospitals in Vietnam, for the first time within the data collection period. Infertility is defined as failure to achieve a clinical pregnancy after 12 months or more of regular unprotected sexual intercourse. ${ }^{17}$ We included both primary and secondary infertility. Primary infertility is infertility occurring in a couple who have never had a child. Secondary infertility is failure to conceive following a previous pregnancy. We excluded patients who did not meet the diagnostic criteria for infertility, such as breastfeeding or postpartum amenorrhea. We also excluded patients who did not agree to participate in the study.

\section{Study setting}

The study was conducted at the Department of Infertility, Tu Du Hospital, Ho Chi Minh City, Vietnam.

\section{Sample size and sampling procedure}

The sample size was calculated using the formula for comparing a proportion with a reference one. Previous evidence has shown that the prevalence of depression could range between $18.5 \%$ and $53.8 \% .^{18-21}$ In this study, we assumed the prevalence (p) of depression in the study population was $50 \%$ to achieve the maximum sample size, which was 386 participants. We selected all participants who visited the Infertility Clinic of Tu Du Hospital and met the inclusion criteria for this study during the period from April to July 2016. In total, there were 401 infertile women involved in this study.

\section{Measurements/instrument}

Data on demographic and socio-economic characteristics of the participants were collected using a structured questionnaire. Details about measurement of demographic and other socio-economic characteristics are presented in the Supplementary material.

The Vietnamese version of the Patient Health Questionnaire (PHQ)-9 was used to measure depressive 
symptoms. PHQ-9 included nine items inquiring about nine DSM-IV criteria for depression. Each item was scored from 0 (not at all) to 3 (nearly every day). ${ }^{22}$ The total score of the nine items of the PHQ-9 (ranging from 0-27) reflect the severity of depressive symptoms. Previous research has shown evidence of validity and reliability of the PHQ-9 among primarily care patients. In a study with 6,000 patients recruited from eight primary care clinics and seven obstetrics-gynecology clinics, the PHQ-9 showed excellent internal consistency (Cronbach's alpha $=0.89$ ), good construct validity, and the ability to distinguish between cases and non-cases with a sensitivity of $88 \%$ and specificity of $88 \%$ (as shown in Table 1) at a cut-off score of $10 .{ }^{14}$ It was concluded from this study that PHQ-9 with the cut-off point of 10 is a useful instrument for obstetricians or medical staff at primary healthcare level to assess mental disorders, psycho-insufficiency, and stress, which are newly formed in their patients. ${ }^{14}$

The PHQ-9 had been translated into Vietnamese, and the reliability and validity of the Vietnamese version had been confirmed. ${ }^{10}$ There have been at least three published studies in Vietnam which successfully applied this validated Vietnamese version of PHQ-9: (1) depression among peri-menopausal women (2009), ${ }^{23}$ (2) depression among late abortion women (2011), ${ }^{24}$ and (3) depression among HIV infected pregnant women (2013). ${ }^{25}$ In the present study, the cut-off score of 10 of the PHQ-9 was used to distinguish between case and non-case of depression. Those who had a total PHQ-9 score of 10 or more would be categorized as having symptoms suggestive of a depression diagnosis.

Table I Operating characteristics of various PHQ-9 cut points for diagnosing major depression*

\begin{tabular}{|l|l|l|}
\hline PHQ-9 score & Sensitivity (\%) & Specificity (\%) \\
\hline$\geq 9$ & 95 & 84 \\
$\geq 10$ & 88 & 88 \\
$\geq 11$ & 83 & 89 \\
$\geq 12$ & 83 & 92 \\
$\geq 13$ & 78 & 93 \\
$\geq 14$ & 73 & 94 \\
$\geq 15$ & 68 & 95 \\
\hline
\end{tabular}

Note: *Patients underwent a structured psychiatric interview by a mental health professional to determine the presence or absence of major depression using DSMIV diagnostic criteria.

Abbreviations: PHQ, Patient Health Questionnaire; DSM, Diagnostic and Statistical Manual of Mental Disorders.

\section{Data collection}

The data collection procedure included the following three steps:

\section{Step I: Questionnaire testing (Pilot study)}

Pilot interviews were conducted with 10 infertile female patients, and several questions were then reworded to ensure better comprehensibility and appropriateness with the local context. The pilot study was also aimed to make research staff familiar with the study procedure. Information obtained from the pilot study were not included in the data of the main study. Three midwives who were working at the Department of Infertility were recruited as research assistants and were trained in the study procedure and ethical conduct of research to conduct interviews both in the pilot study and in the main survey.

\section{Step 2: Participants recruitment}

At the Clinic of Infertility, once a female patient was confirmed as having infertility by the attending physician, she would be invited to participate in the study.

\section{Step 3: Conducting interviews}

Eligible participants would be informed of the study purpose, procedures, and related risks and benefits. Written informed consent was obtained from all participants who agreed to participate in the study. Once the consent form was signed, the principal investigator would invite the patient to a private room within the same Department for an interview, so that privacy and confidentiality would be ensured. Participation was voluntary and the participant could quit the interview at any time without facing any consequences. The interview was conducted without the presence of the husband.

During each interview, the interviewer asked the participant questions in the structured questionnaire. The participant was also asked to complete the PHQ-9 by herself following careful instruction on how to complete the instrument by the interviewer. If the result of the PHQ-9 suggested a depression diagnosis, the patient would then be referred to a mental health service in Ho Chi Minh City, Vietnam. Each interview lasted 30 minutes on average.

\section{Data analysis}

Data was analyzed using STATA 20.0. Distribution of variables were examined using descriptive analyses. Mean and standard deviation were reported for continuous variables, and frequency and proportion were reported for categorical variables. 
To identify factors associated with depressive symptoms, multiple binary logistic regression was used. Bivariate logistic regression analyses were conducted first. All independent variables that had a $P$-value of 0.25 or smaller in bivariate analyses would be included in the multivariable logistic regression model. ${ }^{26}$ Adjusted Odds Ratios (AOR) and their $95 \%$ confidence intervals were reported.

\section{Ethical considerations}

This study was conducted in accordance with the Declaration of Helsinki. Ethics approval for the study was obtained from the Institutional Review Board of Tu Du Hospital $\left(\mathrm{N}_{\mathrm{o}}: 3645 /\right.$ QD-BVTD). The University of Medicine and Pharmacy at HCMC also granted ethical approval for the conduct of the study ( $\mathrm{N}_{\mathrm{o}}$ : 182/DHYD-HD). Informed consent was obtained from all patients. Data were kept anonymous and confidential during all stages of the study.

\section{Results}

We invited 401 women, and none of them refused to participate into the study. The mean age of the participants was 30.41 years $(\mathrm{SD}=4.47)$. Most of them $(76 \%)$ were from distant provinces. None of them were too poor to pay for treatment expenses. Only $30 \%$ of the participants reported following a religion. About $21 \%$ of the sample had higher education, and $12 \%$ had very low education. Regarding occupation, the majority of the participants had a stable job, while $12 \%$ reported doing housework.

Regarding obstetric characteristics, as shown in Table 2, a large proportion of the study sample (87.8\%) were of the nulliparous group (primary infertility), while the proportion of those who belonged to the parous group (secondary infertility) was 7-times lower (12.2\%). Regarding the infertility origin, causes related to the husband accounted for $25.4 \%$, while the proportion of causes related to the wife was 2-times higher; and $9 \%$ of the participants reported causes shared by both husband and wife. The proportion of those who had a child expectation time $<2$ years was comparable to the proportion of those who had a child expectation time of $2-5$ years $(42.1 \%$ vs. $40.9 \%)$. The group with a child expectation time of more than 5 years accounted for the lowest proportion (17\%).

As shown in Table 3, the total score of the PHQ-9 ranged between 0 and 19. The mean score of the PHQ-9 scores was 3.04 ( $\mathrm{SD}=3.75$ ). Of the 401 participants, 49 women had symptoms suggestive of a depression diagnosis (based on the cut-off score of 10 of the PHQ-9). The prevalence of depression
Table 2 Characteristics of study participants

\begin{tabular}{|c|c|c|}
\hline Characteristics & $\begin{array}{l}\text { Total } \\
(n=40 I)\end{array}$ & Percentage \\
\hline \multicolumn{3}{|l|}{ Age in years } \\
\hline Mean \pm SD & $30.4 I \pm 4.47$ & \\
\hline \multicolumn{3}{|l|}{ Living area } \\
\hline Province & 306 & 76.3 \\
\hline City & 95 & 23.7 \\
\hline \multicolumn{3}{|l|}{ Economic status } \\
\hline Sufficient & 352 & 87.8 \\
\hline Well-off & 49 & 12.2 \\
\hline \multicolumn{3}{|l|}{ Marital status } \\
\hline Living with husband & 399 & 99.5 \\
\hline Single mother & 2 & 0.5 \\
\hline \multicolumn{3}{|l|}{ Religion } \\
\hline No & 280 & 69.8 \\
\hline Yes & 121 & 30.2 \\
\hline \multicolumn{3}{|l|}{ Educational level } \\
\hline Primary (grade I-5) & 51 & 12.7 \\
\hline Junior secondary (grade 6-9) & 115 & 28.7 \\
\hline Senior secondary (grade 10-12) & 152 & 37.9 \\
\hline Higher (college or higher level) & 83 & 20.7 \\
\hline \multicolumn{3}{|l|}{ Occupation } \\
\hline Public staff & 133 & 33.2 \\
\hline Farmer & 41 & 10.2 \\
\hline Trader & 44 & 11.0 \\
\hline Worker & 89 & 22.2 \\
\hline Unemployed, house-work & 49 & 12.2 \\
\hline Other & 45 & 11.2 \\
\hline \multicolumn{3}{|l|}{ Childbirth } \\
\hline Nulliparous & 352 & 87.8 \\
\hline Parous & 49 & 12.2 \\
\hline \multicolumn{3}{|l|}{ General infertility causes } \\
\hline By wife & 241 & 60.1 \\
\hline By husband & 102 & 25.4 \\
\hline Unknown & 21 & 5.2 \\
\hline Both & 37 & 9.2 \\
\hline \multicolumn{3}{|l|}{ Infertility treatment to date } \\
\hline $0-6$ months & 285 & 71.1 \\
\hline $7-12$ months & 38 & 9.5 \\
\hline 13-24 months & 44 & 11.0 \\
\hline 24+ months & 34 & 8.5 \\
\hline \multicolumn{3}{|l|}{ Years of child expectation } \\
\hline$<2$ years & 169 & 42.1 \\
\hline $2-5$ years & 164 & 40.9 \\
\hline$>5$ years & 68 & 17 \\
\hline
\end{tabular}

among infertile women in this study was $12.2 \%(95 \%$ CI $=9.1-15.8 \%$ ). 
Table 3 Depression prevalence by PHQ-9 scoring

\begin{tabular}{|l|l|l|l|}
\hline Depression & Total (n) & Prevalence (\%) & $\mathbf{9 5 \%} \mathbf{~ C l}$ \\
\hline No & 352 & 87.8 & $84.1-90.8$ \\
Yes & 49 & 12.2 & $9.1-15.8$ \\
Total & 401 & 100 & \\
\hline
\end{tabular}

Abbreviation: PHQ, Patient Health Questionnaire.

To identify factors associated with depression, bivariate logistic regression analyses were conducted first. Associations between depression and 20 independent variables were examined. There were three variables significantly associated with depression $(P<0.05)$.

In multivariable logistic regression analyses, three variables were found as significantly associated with depressive symptoms among infertile women, namely infertility origin, previous use of antidepressants, and having an alcohol-addicted husband (Table 4). Those who reported infertility causes related to their husband and causes related to both spouses had a 3.09-times higher odds and 3.63-times higher odds of having depressive symptoms, respectively, compared to those who reported causes related to the wife. In addition, those who reported previous use of antidepressants had a 48.1-times higher odds of having depressive symptoms compared to those who did not report previous use of antidepressants. Moreover, the odds of having depressive symptoms among those who had an alcohol-addicted husband was 3.8-times higher than that among those without an alcohol-addicted husband.

\section{Discussion}

The study provided important evidence of the prevalence of depression among infertile women in Vietnam. It was found from our study that the prevalence of depression among infertile women was higher than that among the general population of Vietnam. ${ }^{5}$ However, this prevalence was smaller than the prevalence of depression among infertile women in other populations, as found in studies by Lok et al, ${ }^{19}$ Fatemeh et al, ${ }^{20}$ and Al-Homaidan ${ }^{21}$ (the prevalence was $33 \%, 40.8 \%$, and $53.8 \%$, respectively). This result could be explained by several reasons. First, the depression prevalence in our study was lower than that found in Lok et al's study $(12.2 \%$ vs. $33 \%)$ since the women in our study were infertile female patients seeking medical examination on the first visit to Tu Du Hospital. As they had not experienced treatment failure yet, they might have hope and be optimistic and, therefore, had a better psychological status. Meanwhile, the other study recruited female patients with infertility treatment failures only, and, as a result of multiple treatments and plentiful expenses, they might feel anxious, tired, disappointed, and uncertain, and might be more likely to have depressive symptoms. Second, the studies in other countries used different tools to measure depressive symptoms, including the Beck Depression Inventory (BDI) and the Center for Epidemiologic Study Depression Scale (CES-D), ${ }^{10-12}$ which might result in different prevalences of depression.

Previous studies have reported very high depression prevalence in western countries. ${ }^{27-29}$ There has also been evidence of a strong association between depression and infertility treatment outcomes. ${ }^{30}$ It becomes difficult for women to be fecundated when they are suffering with depression. ${ }^{31}$ Although the prevalence of depression among infertile women in our study was lower than that among infertile women in other countries, ${ }^{18,30}$ it was nearly 4-times as high as that in the general Vietnamese population. ${ }^{32}$ This finding suggests the importance of screening for depression during assisted reproduction. This is especially important given the fact that depression in the context of infertility treatment is not paid due attention by either physicians nor researchers. Depression screening can be done easily within a short period of time by trained medical staff at a clinic. In addition, we recommend that depression examination and screening should be made early at the first visit for infertility treatment to early refer the patient to appropriate mental health and psychological support services, and, thereby, improving the effectiveness of infertility treatment. Evidence from our study would inform an amendment of current guidelines on assisted reproduction. It would also add to themodern concept of comprehensive therapy for infertile patients to improve the effectiveness of infertility treatment in Vietnam.

Comparing the prevalence of depression among our participants with that among other groups of women treated at $\mathrm{Tu}$ Du hospitals, we found that the prevalence of depression among infertile women (12.2\%) was higher than that among women whose children were referred to the newborn nursing department (11.6\%), and lower than that in other groups including post-partum women $(15.2 \%)$, peri-menopausal women $(37.9 \%)$, women with advanced pregnancy termination (41.4\%), hydatidiform mole patients (21.1\%), and HIV-infected pregnant women (13.2\%). ${ }^{16}$ That depressive symptoms were more common among post-partum women and peri-menopausal women could be explained by the fact that they had just 
Table 4 Multivariable analysis of relationship between subjects' characteristics and depression

\begin{tabular}{|c|c|c|c|c|}
\hline Characteristics & No depression $(n=352)$ & Depression $(n=49)$ & Adjusted OR & $P$-value \\
\hline \multicolumn{5}{|c|}{ Participant's education } \\
\hline Primary or lower & $43(84.3)$ & $8(15.7)$ & 1 & \\
\hline Junior secondary & $108(93.9)$ & $7(6.1)$ & 0.37 & 0.114 \\
\hline Senior secondary & $134(88.2)$ & $18(11.8)$ & 0.68 & 0.485 \\
\hline Higher & $67(80.7)$ & $16(19.3)$ & 0.92 & 0.895 \\
\hline \multicolumn{5}{|l|}{ Living area } \\
\hline Province & $272(88.9)$ & $34(11.1)$ & 1 & \\
\hline City & $80(84.2)$ & $15(15.8)$ & 1.01 & 0.975 \\
\hline \multicolumn{5}{|l|}{ Birth giving } \\
\hline No & $305(86.6)$ & $47(13.4)$ & I & \\
\hline Yes & 47 (95.9) & $2(4.1)$ & 0.48 & 0.218 \\
\hline \multicolumn{5}{|l|}{ Infertility origin } \\
\hline Wife & $221(91.7)$ & $20(8.3)$ & I & \\
\hline Husband & $84(82.4)$ & $18(17.6)$ & 3.09 & 0.004 \\
\hline Both & $28(75.7)$ & $9(24.3)$ & 3.63 & 0.017 \\
\hline Unknown & $19(90.5)$ & $2(9.5)$ & 1.75 & 0.496 \\
\hline \multicolumn{5}{|c|}{ Previous assisted reproduction } \\
\hline No & $254(89.1)$ & $31(10.9)$ & I & \\
\hline Yes & $98(84.5)$ & $18(15.5)$ & 1.09 & 0.827 \\
\hline \multicolumn{5}{|c|}{ Previous antidepressant use } \\
\hline No & $35 \mathrm{I}(89.5)$ & $4 I(10.5)$ & I & \\
\hline Yes & I (II.I) & $8(88.9)$ & 48.1 & 0.001 \\
\hline \multicolumn{5}{|c|}{ Alcohol addicted husband } \\
\hline No & $342(88.6)$ & 44 (II.4) & I & \\
\hline Yes & $10(66.7)$ & $5(33.3)$ & 4.83 & 0.017 \\
\hline \multicolumn{5}{|c|}{ Tobacco addicted husband } \\
\hline No & $332(88.3)$ & 44 (11.7) & I & \\
\hline Yes & $20(80.0)$ & $5(20.0)$ & 0.84 & 0.829 \\
\hline \multicolumn{5}{|l|}{ Being disparaged } \\
\hline No & $225(89.6)$ & $26(10.4)$ & 1 & \\
\hline Yes & $127(84.7)$ & $23(15.3)$ & 1.72 & 0.127 \\
\hline
\end{tabular}

Note: Bold data show the associations are significant.

experienced the tough process of birth delivery and impacts of female endocrine changes, respectively. In addition, the diagnosis and treatment process for those with advanced pregnancy termination, hydatidiform mole, HIV-infected pregnancy might be very tiring, result in the feeling of uncertainty and cause high levels of psychological distress. In our study, the measurement of depressive symptoms was conducted when the patients came to the hospital for the first time to seek treatment. These women might still have much hope and be positive about the treatment outcomes, hence were less likely to have depressive symptoms compared to the other patient groups.
This study provides useful insight of correlates of depressive symptoms among Vietnamese infertile women. We found that those who had infertility causes related to the husband and those who had infertility causes related to both spouses were more likely to report depressive symptoms. This finding was consistent with previous studies conducted in other countries that confirmed a worse psychological impact of having an infertility diagnosed husband or combined infertility. ${ }^{20,33-35}$ In addition, our study also found a significant association between previous antidepressant use and current depressive symptoms among infertile women, which is similar to findings from research by Casilla-Lennon et al. ${ }^{36}$ 
This study also found that having an alcohol-addicted husband could significantly increase the risk of having depressive symptoms among infertile women. There has been research evidence showing that symptoms of depression can arise or get exacerbated within the context of a variety of different interpersonal stressors, and alcohol problems related to the marital relationship are predictive of depressive symptoms among wives. ${ }^{34,35,37}$ Infertility and related stresses may influence one partner's drinking behavior as a way of coping with negative affect, and at the same time may influence the negative affect of the other partner. ${ }^{37}$

Our findings provided useful implications for clinical practice. Specifically, apart from inquiring about infertility-related information, asking patients about their history of antidepressant use and about their spouse's substance use behaviors might be useful in identifying groups of infertile women who are at higher risk of having depressive symptoms. In addition, early intervention for these high-risk groups might be beneficial in improving their psychological well-being.

Several limitations should be taken into consideration when interpreting the findings of our study. First, due to the cross-sectional design, causal relationships could not be established between depression and independent variables. Second, the data of the study were collected from one hospital, hence the findings cannot be generalized to the population of infertile women of the whole country. However, as Tu Du Hospital is the largest center of infertility treatment in Vietnam, where almost all infertility patients in the south are admitted, the study provides important evidence regarding mental health and its correlates among infertile women in Vietnam, and the findings may be of relevance to other developing countries. Future studies of national scale and with longitudinal design covering the whole course of the infertility treatment are recommended for a more representative and comprehensive picture of depression and its risk factors among infertile women in Vietnam.

\section{Conclusion}

To sum up, our study provided evidence of a high level of depression among a sample of Vietnamese infertile women and its correlates. The study findings suggest the need for screening for depression among women seeking treatment for infertility. Special attention should be paid to groups that have characteristics associated with higher risks of depression, including having infertility causes related to husband or both spouses, having previously used antidepressants, and having an alcohol-addicted spouse.

\section{Availability of data}

Data are available upon request to the corresponding author.

\section{Acknowledgments}

We are indebted to the participants for making this research possible and to all physicians and staff of $\mathrm{Tu}$ Du Hospital, Department of Infertility. The research was funded by Tu Du Hospital, Vietnam. The funding organization did not have any role in the design, data collection, or interpretation of the findings in the manuscript.

\section{Author contributions}

All authors made substantial contributions to conception and design, acquisition of data, or analysis and interpretation of data; took part in drafting the article or revising it critically for important intellectual content; gave final approval of the version to be published; and agree to be accountable for all aspects of the work.

\section{Disclosure}

The authors report no conflicts of interest in this work.

\section{References}

1. Zegers-Hochschild F, Adamson GD, de Mouzon J, et al. International Committee for Monitoring Assisted Reproductive Technology (ICMART) and the World Health Organization (WHO) revised glossary of ART terminology. Fertil Steril. 2009;92(5):1520-1524. doi:10.1016/j.fertnstert.2009.09.009.

2. Chandra A, Copen CE, Stephen EH. Infertility and impaired fecundity in the United States, 1982-2010: data from the National Survey of Family Growth. Natl Health Stat Report. 2013;(67):1-18.

3. Cousineau TM, Domar AD. Psychological impact of infertility. Best Prac Res Clin Obstet Gynaecol. 2007;21(2):293-308. doi:10.1016/j. bpobgyn.2006.12.003

4. World Health Organisation. Global Health Estimates 2016: Disease burden by Cause, Age, Sex, by Country and by Region, 2000-2016. Geneva: World Health Organization; 2018. Available from: https:// www.who.int/healthinfo/global_burden_disease/estimates/en/index1. html. Accessed May 13, 2019.

5. Peterson BD, Newton CR, Feingold T. Anxiety and sexual stress in men and women undergoing infertility treatment. Fertil Steril. 2007;88 (4):911-914. doi:10.1016/j.fertnstert.2006.12.023

6. Kaplan SS, Sadock VA. Synopsis of psychiatry: behavioral sciences/ clinical psychiatry, 10(th) edition. Indian J Psychiatry. 2009;51(4):331.

7. Tsai C-F, Juang K-D, Chang S-P, Chen T-H. Prevalence of depressive and anxiety disorders in an assisted reproductive technique clinic. Hum Reprod. 2004;19(10):2313-2318. doi:10.1093/humrep/deh414

8. Neter E, Goren S. Infertility centrality in the woman's identity and goal adjustment predict psychological adjustment among women in ongoing fertility treatments. Int J Behav Med. 2017;24:880-892. doi:10.1007/s12529-017-9693-9 
9. Abbey A, Andrews FM, Halrnan LJ. Gender's role in response to infertility. Psychol Women Q. 1991;15(2):295-316. doi:10.1111/ j.1471-6402.1991.tb00798.x

10. Nguyen TQ, Bandeen-Roche K, Bass JK, German D, Nguyen NT, Knowlton AR. A tool for sexual minority mental health research: the Patient Health Questionnaire (PHQ-9) as a depressive symptom severity measure for sexual minority women in Viet Nam. J Gay Lesbian Ment Health. 2016;20(2):173-191. doi:10.1080/ 19359705.2015.1080204

11. Fisher J, Tran TD, Biggs B, Dang TH, Nguyen TT, Tran T. Intimate partner violence and perinatal common mental disorders among women in rural Vietnam. International Health. 2013;5(1):29-37.

12. Fisher J, Tran T, Nguyen TT, Nguyen H, Tran TD. Common mental disorders among women, social circumstances and toddler growth in rural Vietnam: a population-based prospective study. Child Care Health Dev. 2015;41(6):843-852. doi:10.1111/cch.12235

13. Khanh D. What Explains the Association between Socioeconomic Status and Depression among Vietnamese Adults?. Brisbane: Queensland University of Technology; 2011.

14. Amstadter A, Acierno R, Richardson L, et al. Typhoon prevalence of postraumatic stress disorder, major depressive disorder, panic disorder, generalized anxiety disorder in a Vietnamese sample. J Trauma Stress. 2009;22(3):180-188. doi:10.1002/jts.20404

15. Tudu Obtestric and Gyneacology hospital. Annual hospital report. Ho chi Minh city, Vietnam: Tudu Obtestric and Gyneacology hospital; 2016.

16. Tudu Obtestric and Gyneacology hospital. Annual hospital report. Ho chi Minh city, Vietnam: Tudu Obtestric and Gyneacology hospital; 2015.

17. Fritz MA. Clinical Gynecologic Endocrinology and Infertility. 8th ed. Philadelphia: Wolters Kluwer Health; 2014.

18. Rotenstein LS, Ramos MA, Torre M, et al. Prevalence of depression, depressive symptoms, and suicidal ideation among medical students: a systematic review and meta-analysis. JAMA. 2016;316 (21):2214-2236. doi:10.1001/jama.2016.17324

19. Lok IH, Lee DTS, Cheung LP, Chung WS, Lo WK, Haines CJ. Psychiatric morbidity amongst infertile chinese women undergoing treatment with assisted reproductive technology and the impact of treatment failure. Gynecol Obstet Invest. 2002;53(4):195-199. doi: $10.1159 / 000064560$

20. Ramezanzadeh F, Aghssa MM, Abedinia N, et al. A survey of relationship between anxiety, depression and duration of infertility. BMC Women 'S Health. 2004;4(1):9. doi:10.1186/1472-6874-4-9

21. Al-Homaidan HT. Depression among women with primary infertility attending an infertility clinic in Riyadh, kingdom of Saudi Arabia: rate, severity, and contributing factors. Int J Health Sci. 2011;5 (2):108-115

22. Kroenke K, Spitzer RL, Williams JB. The PHQ-9: validity of a brief depression severity measure. J Gen Intern Med. 2001;16(9):606-613.

23. Nguyen H, Vo. T. Prevalence and risks factors of depression among perimenopausal women. Med Rev Ho Chi Minh City. 2009;N13:S1: p87-p91.
24. Tuan V, Nguyen P. Prevalence and risk factors of depression among late abortion women. Med Rev Ho Chi Minh City. 2011;N16:S1: p247-p250.2012.

25. Nguyen T, Vo. T. Prevalence and risk factors of depression among HIV infected pregnant women who were checked up at HungVuong hospital. Med Rev Ho Chi Minh City. 2013;N17:S1:p105-p109.

26. Hosmer D. Applied Logistic Regression. Hoboken. New Jersey: Wiley; 2013.

27. Alonso J, Angermeyer MC, et al; TEM Investigators. Prevalence of mental disorders in Europe: results from the European Study of the Epidemiology of Mental Disorders (ESEMeD) project. Acta Psychiatr Scand. 2004;109(s420):21-27. doi:10.1111/j.16000047.2004.00325.x.

28. Henderson S, Andrews G, Hall W. Australia's mental health: an overview of the general population survey. Aus $N Z J$ Psychiatry. 2000;34(2):197-205. doi:10.1080/j.1440-1614.2000.00686.x

29. Akhtar-Danesh N, Landeen J. Relation between depression and sociodemographic factors. Int J Ment Health Syst. 2007;1(1):4. doi:10.1186/1752-4458-1-4

30. Paulina Gdańska AUED-JAUBGAUMR-ZAUPWAUMW. Anxiety and depression in women undergoing infertility treatment. Ginekologia Polska. 2017;88(2):109-112.

31. Zorn B, Auger J, Velikonja V, Kolbezen M, Meden-Vrtovec H. Psychological factors in male partners of infertile couples: relationship with semen quality and early miscarriage. Int J Androl. 2008;31 (6):557-564. doi:10.1111/j.1365-2605.2007.00806.x

32. Vuong DA, Van Ginneken E, Morris J, Ha ST, Busse R. Mental health in Vietnam: burden of disease and availability of services. Asian J Psychiatr. 2011;4(1):65-70. doi:10.1016/j.ajp.201 1.01 .005

33. Drosdzol A, Skrzypulec V. Depression and anxiety among Polish infertile couples - an evaluative prevalence study. J Psychosom Obstet Gynecol. 2009;30(1):11-20. doi:10.1080/01674820902830276

34. Mikulincer M, Horesh N, Levy-Shiff R, Manovich R, Shalev J. The contribution of adult attachment style to theadjustment to infertility. $\mathrm{Br} J$ Med Psychol. 1998;71:265-280. doi:10.1111/ papt.1998.71.issue-3

35. Sheiner E, Sheiner EK, Potashnik G, Carel R, Shoham-Vardi I. The relationship between occupational psychological stress and female fertility. Occup Med (Chic Ill). 2003;53(4):265-269.

36. Casilla-Lennon MM, Meltzer-Brody S, Steiner AZ. The effect of antidepressants on fertility. Am J Obstet Gynecol. 2016;215(3):314. e311-314.e3145. doi:10.1016/j.ajog.2016.01.170

37. Homish GG, Leonard KE, Kearns-Bodkin JN. Alcohol use, alcohol problems, and depressive symptomatology among newly married couples. Drug Alcohol Depend. 2006;83(3):185-192. doi:10.1016/j. drugalcdep.2005.10.017

38. American Psychiatric Association. Diagnostic and statistical manual of mental disorders. 5th ed. Washington, DC: American Psychiatric Association. 2013. 


\section{Supplementary material}

Demographic variables were defined and collected, including:

(1) Study subject's and husband's age was calculated as year of study minus year of birth.

(2)Marital status was a binary variable with two values of single or cohabiting. Single was women who had ever been married and diagnosed as having infertility, but then divorced and lived alone. They visited the hospital with the desire for infertility treatment.

(3) Economic status was a nominal variable, with ordinal values of just enough for living or relatively wealthy that were defined on subjective assessment.

(4) Anxiety of family had two values of YES (when the answer included one of the following factors: child loss, relative loss, family pressure on child) or $\mathrm{NO}$ (when those factors did not exist).

(5) Alcohol abuse was based on the International Classification of Diseases ICD-10, alcohol abuse was diagnosed when three of the following criteria existed within at least one recent year:

- vigorous desire that was unable to stop and forced to go on.

- alcohol intake decrease or termination was very difficult.

- evidence of increased alcohol tolerance, like increased volume consumption.

- gradually ignoring hobbies which had been preferred before.

- continuation of alcohol intake, despite harm being known.
(6) Tobacco abuse, as per American Psychological Association (APA), a tobacco smoker who has at least three of the following criteria for a minimal period of 12 months is tobacco-addicted (in line with DSM-V): ${ }^{1}$

- number of cigarettes increases day by day.

- upon tobacco shortage or abstinence, smokers feel restless, upset, depressed, angry, have problems concentrating, etc. Those discomforts disappear upon smoking resumption.

- smoking time longer than expected. For instance, a smoker intends to smoke for a working duration or during stress in life and plans to stop smoking after things are solved, but continues to smoke anyway, or plans to smoke outdoors only, not in front of children, but while at home, sometimes desires to break the plan.

- wants or tries to stop smoking many times, but fails.

- finds plenty of time to use tobacco and smoke.

- reduces or gives up social activities due to tobacco.

- continues to smoke, although harmful impacts are already known or is already suffering from smoking-related problems.

\section{References}

1. American Psychiatric Association. Diagnostic And Statistical Manual Of Mental Disorders. 5th ed. Washington, DC: American Psychiatric Association; 2013.

\section{Publish your work in this journal}

The International Journal of Women's Health is an international, peerreviewed open-access journal publishing original research, reports, editorials, reviews and commentaries on all aspects of women's healthcare including gynecology, obstetrics, and breast cancer. The manuscript management system is completely online and includes a very quick and fair peer-review system, which is all easy to use. Visit http://www.dovepress.com/testimonials.php to read real quotes from published authors. 